\title{
Editorial
}

\section{The New Era of Gastric Cancer in the East and West: Have Our Approaches Harmonized?}

\author{
Vivian E. Strong \\ Gastric and Mixed Tumor Service, Department of Surgery, Memorial Sloan-Kettering Cancer Center, New York, N.Y., USA
}

In this special issue of Digestive Surgery on gastric cancer, authorities from around the world have contributed to this comprehensive compendium that highlights and summarizes our current understanding. Differences in disease-specific survival of gastric cancer patients endemic to the Eastern hemisphere compared to the Western hemisphere have, unfortunately, historically encouraged a division of thinking and approaches to treatment for a disease that may be more similar than previously thought.

Many practice-changing advances have been made just in the past few years - the field is dynamic. Contributions include improvements in staging and treatment that have been of significant impact in the East and West. For one, neoadjuvant treatment approaches for locally advanced gastric tumors have improved survival and changed clinical practice such as outlined by the MAGIC trial, which evaluated perioperative chemotherapy with epirubicin, cisplatin, and 5-fluorouracil to surgery alone and demonstrated a significant survival benefit with perioperative chemotherapy [1]. A combination of both novel and effective adjuvant treatment regimens from the West and East have further expanded treatment options to adjuvant chemotherapy combinations [2], chemotherapy + radiation $[3,4]$, or single-agent adjuvant therapy $[5$, 6] to name just a few.

Similarly, the East and West have begun to resolve differences on the long-debated topic of lymphadenectomy. In the West, the updated Dutch trial has led Western sur- gical oncologists to understand the importance of a D2 lymphadenectomy as a superior approach to D1 [7]. In the East, the Japanese randomized control trial of D3 versus $\mathrm{D} 2$ lymphadenectomy demonstrated that a $\mathrm{D} 2$ resection affords similar disease-specific survival with less morbidity. It appears that on this topic, the East and West have finally harmonized [8].

From a technical perspective, both the East and West have applied technologic advances to minimally invasive approaches for selected patients with gastric cancer. The East has blazed this trial. For example, with their unique and large cohort of early gastric cancer patients, they have rigorously evaluated approaches such as endoscopic mucosal resection for early gastric cancer.

In their comprehensive and illuminating chapter, Dr. Yang and Dr. Lee [pp. 132-141] elegantly summarize significant advances in application of minimally invasive approaches to gastric cancer resection. The laparoscopic approach to gastrectomy has been led by surgeons from the Eastern hemisphere, where the increased incidence of gastric cancer and earlier-stage disease predominate. The randomized controlled trials (mostly from the East) outlined by Dr. Yang and Dr. Lee, established this approach as feasible, safe, and oncologically sound. They outline and discuss the many randomized prospective studies that have been completed for the purpose of assuring the safety and efficacy of this treatment approach. It is interesting that few areas have accumulated so many evidence-based

\section{KARGER}

E-Mail karger@karger.com

www.karger.com/dsu
(C) 2013 S. Karger AG, Basel

0253-4886/13/0302-0130\$38.00/0
Vivian E. Strong, MD, FACS

Gastric and Mixed Tumor Service, Department of Surgery Memorial Sloan-Kettering Cancer Center

1275 York Avenue, H-1217, New York, NY 10065 (USA)

E-Mail strongv@ mskcc.org 
studies to vet a new approach. The one caveat of the findings presented is that the learning curve for this procedure is daunting. In many parts of Asia, the incidence of gastric cancer, and predominance of early-stage disease, allow specialty centers to develop and refine this approach. However, in most Western countries, gastric cancer has not reached the volume nor do the cases aggregate to specialty centers in more than a few sites to allow surgeons to excel at this approach. As such, the Western hemisphere, burdened with more advanced-stage disease and patients with more comorbidities, have accepted and adopted the minimally invasive approach, but more slowly.

The issues of the learning curve are salient. Dr. Yang and Dr. Lee discuss the use of robotics and potential technical advantages. They also acknowledge the significant health care costs. Yet, while perhaps utilization of robotic technology will shorten the learning curve, it is clear that the cost/benefit must be more fully evaluated. Nevertheless, such advances have set the course for many centers which now apply laparoscopic and robotic approaches for their patients. Both the East and West acknowledge and endorse minimally invasive approaches for well-selected patients done in centers with sufficient volume.

Accomplishments such as those of Dr. Yang highlight the steadfast interest in improving our understanding of gastric cancer as a disease process and in improving treatment for our patients. It is through such collaborative interests of gastric cancer specialists in the East and West that we are rapidly increasing our understanding of gastric cancer and its variable behavior. Gene expression analysis has refined our understanding of the complex heterogeneity of gastric cancer. Evidence clearly demon- strates that gastric cancer is not just one disease, but several different cancers, each with its unique epidemiologic and histologic profiles. At least three distinct types of gastric cancer are now recognized: distal intestinal-type gastric cancer associated with chronic gastritis and perhaps Helicobacter pylori infection, proximal intestinal-type gastroesophageal cancers which are more aggressive and associated with factors such as obesity and gastroesophageal reflux disease, and diffuse signet-ring cell type cancers that are widely infiltrative and not associated with gastritis [9]. Such understanding has further improved our ability to compare gastric cancer outcomes in the East and West as we realize that results are more similar than previously thought when we compare the same types of gastric cancer subtypes [10].

Whereas prior comparisons were made among all types of gastric cancer, we now recognize the importance of comparing similar types of gastric cancer with regard to survival and outcomes and to jointly evaluate new approaches, whether neoadjuvant/adjuvant or technical. The next step will be to apply our combined understanding and talents to better tailor treatment to these specific subtypes of gastric cancer. Improved understanding of the disease and its subtypes will thus allow for better collaborative investigations into inherent biologic signatures of these different subtypes. This will further encourage the East and West to join forces in our common mission to better understand and improve treatment for our patients. Interestingly, we started the battle separately, but now realize that there is much more in common than previously imagined and that we can forge new ground together. It is an exciting start of a new era - let's move forward.

\section{References}

-1 Cunningham D, Allum WH, Stenning SP, Thompson JN, Van de Velde CJ, Nicolson M, Scarffe JH, Lofts FJ, Falk SJ, Iveson TJ, Smith DB, Langley RE, Verma M, Weeden S, Chua YJ, MAGIC Trial Participants: Perioperative chemotherapy versus surgery alone for resectable gastroesophageal cancer. N Engl J Med 2006;355:11-20.

-2 Bang YJ, Kim YW, Yang HK, Chung HC, Park YK, Lee KH, Lee KW, Kim YH, Noh SI, Cho JY, Mok YJ, Kim YH, Ji J, Yeh TS, Button P, Sirzén F, Noh SH, CLASSIC Trial Investigators: Adjuvant capecitabine and oxaliplatin for gastric cancer after D2 gastrectomy (CLASSIC): a phase 3 open-label, randomised controlled trial. Lancet 2012;379: 315-321.

$\checkmark 3$ MacDonald JS, Smalley SR, Benedetti J, et al: Chemoradiotherapy after surgery compared with surgery alone for adenocarcinoma of the stomach or gastroesophageal junction. $\mathrm{N}$ Engl J Med 2001;345:725-730.

4 Lee J, Lim do H, Kim S, Park SH, Park JO, Park YS, Lim HY, Choi MG, Sohn TS, Noh JH, Bae JM, Ahn YC, Sohn I, Jung SH, Park CK, Kim KM, Kang WK: Phase III trial comparing capecitabine plus cisplatin versus capecitabine plus cisplatin with concurrent capecitabine radiotherapy in completely resected gastric cancer with D2 lymph node dissection: the ARTIST trial. J Clin Oncol 2012;30:268-273.

$\checkmark 5$ Nakajima T, Kinoshita T, Nashimoto A, et al: Randomized controlled trial of adjuvant uracil-tegafur versus surgery alone for serosanegative locally advanced gastric cancer. $\mathrm{Br} \mathrm{J}$ Surg 2007;94:1468-1476.

-6 Sasako M, Sakuramoto S, Katai H, Kinoshita T, Furukawa H, Yamaguchi T, Nashimoto A, Fujii M, Nakajima T, Ohashi Y: Five-year outcomes of a randomized phase III trial com- paring adjuvant chemotherapy with S-1 versus surgery alone in stage II or III gastric cancer. J Clin Oncol 2011;29:4387-4393.

$>7$ Hartgrink HH, van de Velde CJ, Putter H, et al: Extended lymph node dissection for gastric cancer: who may benefit? Final results of the randomized Dutch gastric cancer group trial. J Clin Oncol 2004;22:2069-2077.

8 Sasako M, Sano T, Yamamoto S, et al: D2 lymphadenectomy alone or with para-aortic nodal dissection for gastric cancer. $\mathrm{N}$ Engl J Med 2008;359:453-462.

-9 Shah MA, Khanin R, Tang L, et al: Molecular classification of gastric cancer: a new paradigm. Clin Cancer Res 2011;17:2693-2701.

10 Strong VE, Song KY, Park CH, et al: Comparison of disease-specific survival in the United States and Korea after resection for early-stage node-negative gastric carcinoma. J Surg Oncol 2013;107:634-640. 